\title{
Improved Enantioselective Enzymatic Synthesis of (S) - Pregabalin
}

\author{
Suresh babu Jayachandra, Madhuresh Sethi*, Vipinkumar Kaushik, Vijayakrishna Ravi, Sanjay Mahajan, Mujahid \\ Sufi Ahmed, Bhairaiah Mara, Gurleen Kaur and Purbita Chakraborty
}

$R \& D$, Mylan Laboratories Ltd, India

Received: 㠿 January 23, 2018; Published: 眥 February 15, 2018

*Corresponding author: Madhuresh Sethi, R \& D, Mylan Laboratories Ltd, Plot No: 31, 32, 33 and 34 A ANRICH Industrial Estate, Andhra Pradesh, India, Tel: 918008001545; Email: madhuresh.sethi@mylan.in

\begin{abstract}
The manuscript aims to throw light on the route of synthesis of (3S)-3-(Amino methyl)-5-methylhexanoic acid: (PREGABALIN), which is a cost effective and efficient route. Pregabalin is a drug that is used in the treatment of epilepsy, neuropathic pain, fibromyalgia, and generalized anxiety disorder. This process of synthesis makes use of a liquid enzyme to avoid cost hike and improves the overall chiral purity of the final product accompanied with improved higher yields and purity. The investigational studies performed in this article will help improve the existing processes in certain aspects as discussed above.
\end{abstract}

\section{Introduction}

Pregabalin is available in the market under the brand name of Lyrica among others. It is a drug of choice for the treatment of epilepsy, fibromyalgia, sweeping anxiety disorder and neuropathic pain. It effectively relieves neuropathic pain (pain from damaged nerves) that occurs in your arms, hands, fingers, legs, feet, or toes if you are diabetic or in the area of your rash if you once were affected with shingles (a rash that occurs due to infection with herpes zoster and is also painful) [1]. Pregabalin also finds use in the treatment of fibromyalgia (which is a long-lasting condition causing pain, fatigue, muscle stiffness, tenderness of muscles and difficulty in falling asleep or staying asleep [1]. Pregabalin is used in combination therapy with certain other medications for the treatment of various types of seizures in people who have epilepsy. Pregabalin comes under the class of medications that are known as anticonvulsants [2].

In 1990, Pregabalin was synthesized as an anticonvulsant and was invented by medicinal chemist Richard Bruce Silverman at Northwestern University of Chicago, Illinois [3]. The drug received approval in the European Union in the year of 2004. The US also received FDA approval for its use in treatment of epilepsy, post-therapeutic neuralgia and diabetic neuropathic pain in the December of 2004. It was launched in the US market as Lyrica in the fall of 2005 [4]. Pregabalin also received approval in the European Union and Russia (not in US) for treating generalized anxiety disorder [5].

\section{Mechanism of action}

Pregabalin's mechanism of action involves reducing the number of pain signals that are sent to the brain by the damaged nerves in the body by binding to certain areas in the brain, which helps reducing nerve pain, seizures, and anxiety (Figure 1) [6]. Pregabalin usually binds to the alpha-2-delta site in the neuron with great affinity and decreases the release of many neurotransmitters that are Ca-dependent (For ex: Glutamate). As it is classified as a GABA (gamma amino butyric acid) analogue, this leads to increase in the levels of GABA in the neurons and subsequent reduction in the associated neuropathic pain, due to its anxiolytic and anticonvulsive effects [7].

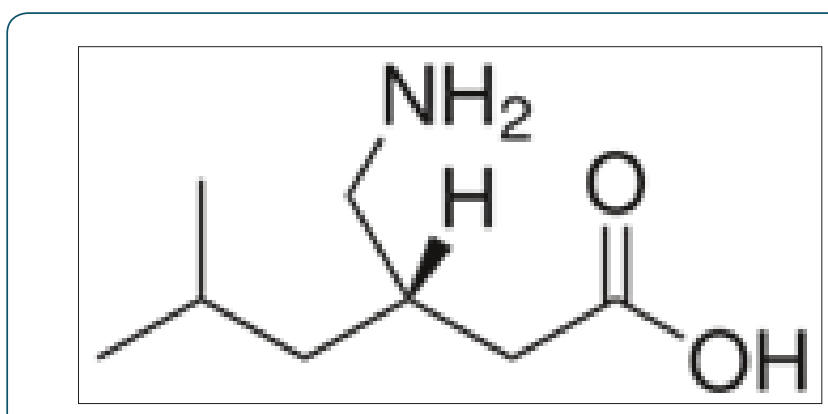

Figure 1: Pregabalin structure.

The common side effects of Pregabalin include [8]:

i. Sleepiness or drowsiness 

ii. Confusion
iii. Forgetfulness
iv. Poor motor coordination
v. Dry mouth
vi. Vision related problems
vii. Weight gain

There are also some potentially serious side effects of Pregabalin [8]:

i. Angioedema

ii. Drug misuse or addiction

iii. Increased risk of suicide

Also, high doses of Pregabalin consumption over a longer period of time might lead to addiction. However, if prescribed dose is taken, the risk of addiction is low. (3S)-3-(Amino methyl)5-methylhexanoic acid (PREGABALIN) is of great importance and the current procedure of its preparation had much scope of improvement and hence it was felt worthwhile to examine an alternate means to prepare this compound (Figure 1).

\section{Material and Methods}

\section{Enzymes}

TL lipase liquid was purchased from Advanced enzymes.

\section{Chemical reagents}

Isovaleraldehyde was purchased from Spectrochem

\section{Analytical Methods}

Gas chromatography: Gas chromatographic analysis during the preparation of 2-carbethoxy-5-methyl hex-2-enoic acid ethyl ester and 2-carbethoxy-3-cyano-5-methyl hexanoic acid ethyl ester was performed on Agilent Technologies Gas chromatography instrument using DB-1, (30 m $\times 0.53 \mathrm{~mm}, 3.0 \mu \mathrm{m})$ capillary column. The elution was carried out with nitrogen as carrier gas and the eluents were detected by Flame ionization detector. The retention time was $19.2 \mathrm{~min}$ and $20.18 \mathrm{~min}$ for the preparation of 2-carbethoxy-5-methyl hex-2-enoic acid ethyl ester and 2-carbethoxy-3-cyano-5-methyl hexanoic acid ethyl ester.

Mass Spectrometry: Electron Spray Ionization-Mass spectra (ESI-MS) was measured using Agilent 1100 LC/MSD Trap SL instrument.

NMR spectra: 1H NMR spectra was recorded on a Bruker Avance $300 \mathrm{MHz}$ spectrometer. The spectra was recorded with $\mathrm{CDCl} 3$ as solvent and trimethylsilane (TMS) as an internal standard for measuring chemical shifts. A region from $0-6$ ppm was scanned for all the samples.

Specific Optical Rotation: Specific optical rotation was measured using Perkin-Elmer 243 polarimeter. The specific optical rotation of the compounds were measured at the sample concentration of $1.1 \% \mathrm{w} / \mathrm{v}$ in methanol at $25^{\circ} \mathrm{C}$.

\section{Results and Discussion}

The preparation of Pregabalin involves 4 reaction steps which will be studied in this manuscript and will be discussed in detail illustrating some noteworthy observations for an improved process.

\section{Preparation of 2-carbethoxy-5-methyl hex-2-enoic acid ethyl ester}

This reaction involves the well-known naming reaction Claisen condensation between isovaleraldehyde and diethyl malonate in the presence of di-n-propyl amine and acetic acid and refluxed azeotropically to obtain ene-diester. In the reported procedure, the reactants Di-n-propyl amine and acetic acid were added in two lots, one in the starting, and other after $4 \mathrm{hrs}$. In our process, we added acetic acid and di-n-propyl amine in the starting only and that too 0.05 equivalent of di-n-propyl amine and 0.13 equivalent of acetic acid, in catalytic amount, that results in cost reduction and increased HPLC purity, with no change in the overall yield (Scheme 1).

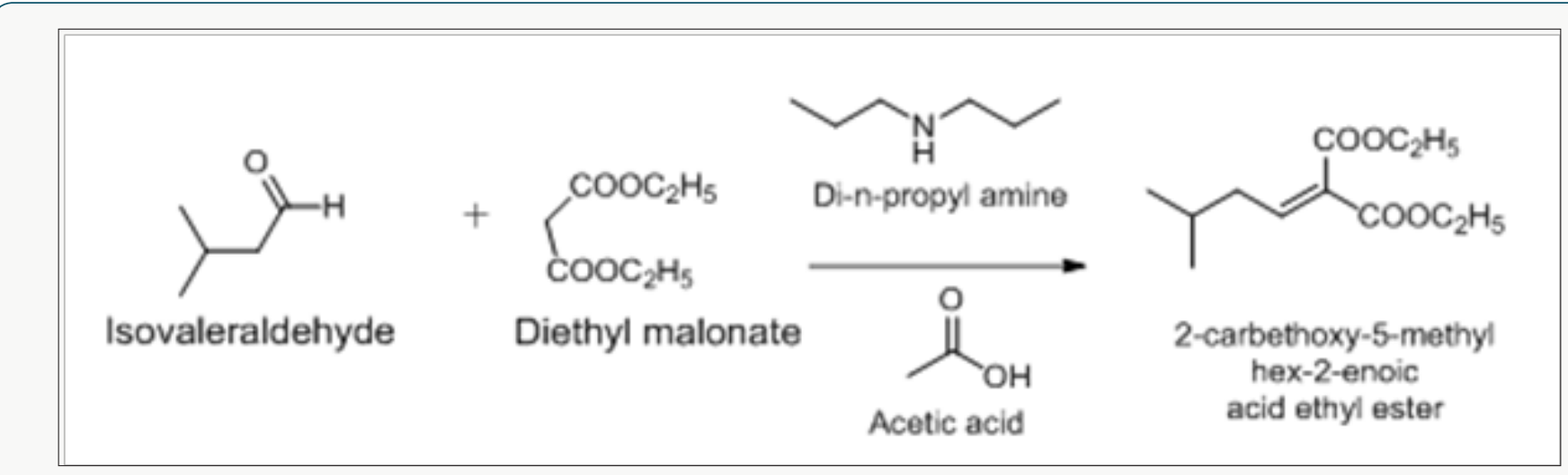

Scheme 1: Preparation of 2-carbethoxy-5-methyl hex-2-enoic acid ethyl ester. 


\section{Preparation of 2-carbethoxy-3-cyano-5-methyl hexanoic acid ethyl ester}

Sodium Cyanide was used instead of Potassium Cyanide that is recommended in the reported procedure. $\mathrm{NaCN}$ is much safer to handle when compared to KCN in industrial use, hence, the change was made. The reported procedure also mentioned distillation of the reaction solvents at $70-1000 \mathrm{C}$ but this gave rise to decreased yield of (S)-3-cyano-5-methyl-hexanoic acid ethyl ester. Hence, an alternative was taken of vacuum distillation, which corrected the yield in a positive way (Scheme 2 ).

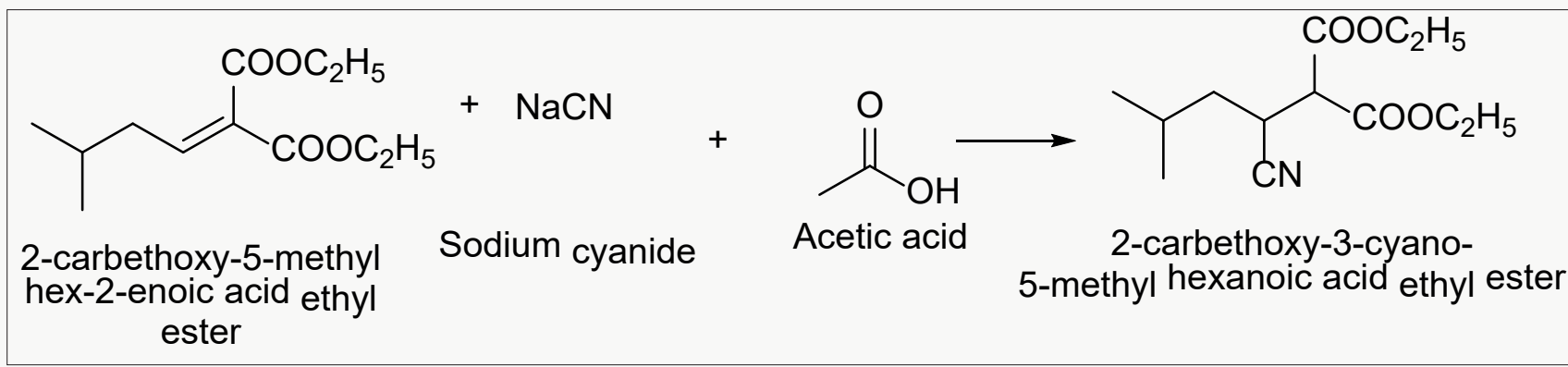

Scheme 2: Preparation of 2-carbethoxy-3-cyano-5-methyl hexanoic acid ethyl ester.

\section{Preparation of (S)-3-cyano-5-methyl-hexanoic acid ethyl ester salt}

This reaction involves selective enzymatic hydrolysis using liquid enzyme TL lipase liquid to form sodium salt of 2-Carboxy ethyl-3-Cyano-5-Methyl hexanoic acid, which was then further acidified with Hydrochloric acid to give 2-Carboxy ethyl-3-Cyano5-Methyl hexanoic acid, which was then treated with t-butyl amine and S (-)-alpha methyl benzylamine to form its corresponding salt. These salts can be further converted to (S)-3-cyano-5-methylhexanoic acid ethyl ester and finally to Pregabalin (Scheme 3).

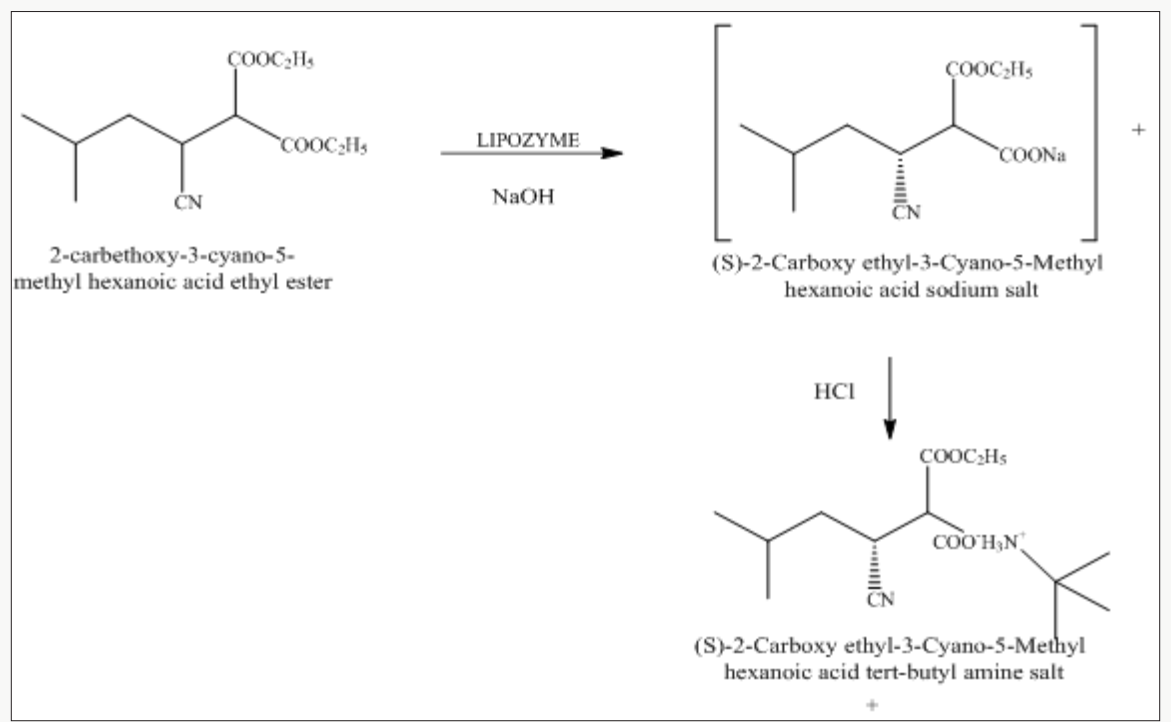

Scheme 3: Preparation of 2-Carboxy ethyl-3-Cyano-5-Methyl hexanoic acid tert-butyl amine salt.

Some of the other enzymes were screened in our lab, out of which reaction proceeded only with immobilized enzyme but the overall cost is affected because of the high market price of the immobilized enzyme over liquid enzyme. Since no significant change in the overall yield was found, we also proceeded with TL Lipase liquid to have more of an economical process (Table 1).=

The 2-Carboxy ethyl-3-Cyano-5-Methyl hexanoic acid when isolated was found to be unstable and hence, 2-Carboxy ethyl-3Cyano-5-Methyl hexanoic acid tert-butyl amine salt was prepared in-situ (Table 2). The chirality of the 2-Carboxy ethyl-3-Cyano5-Methyl hexanoic acid tert-butyl amine salt was checked by its Specific Optical Rotation (SOR) which was found to be 33.480 (for the R-isomer) and -36.80 (for the S-isomer).

\section{Preparation of (S)-3-cyano-5-methyl-hexanoic acid ethyl ester}

Preparation of (S)-3-cyano-5-methyl-hexanoic acid ethyl ester was done in situ in this step, without isolation of 2-Carboxy ethyl3-Cyano-5-Methyl hexanoic acid tert-butyl amine salt (Scheme 4). 
Table 1: List of enzymes screened.

\begin{tabular}{|c|c|c|}
\hline Enzyme used & Yield of (S)-3-cyano-5-methyl Hexanoic acid ethyl ester & Reaction time \\
\hline TL Lipase Immobilized & $0.27 \mathrm{w} / \mathrm{w}$ & $24 \mathrm{hrs}$ \\
\hline Novozym 435 & No reaction occurred & 14 days \\
\hline TL Lipase liquid & $0.27 \mathrm{w} / \mathrm{w}$ & $24 \mathrm{hrs}$ \\
\hline
\end{tabular}

Table 2: Comparison data.

\begin{tabular}{|c|c|}
\hline Intermediate name & Percentage purity \\
\hline 2-Carboxy ethyl-3-Cyano-5-Methyl hexanoic acid & $63 \%$ \\
\hline 2-Carboxy ethyl-3-Cyano-5-Methyl hexanoic acid tert-butyl amine salt & $99 \%$ \\
\hline
\end{tabular}

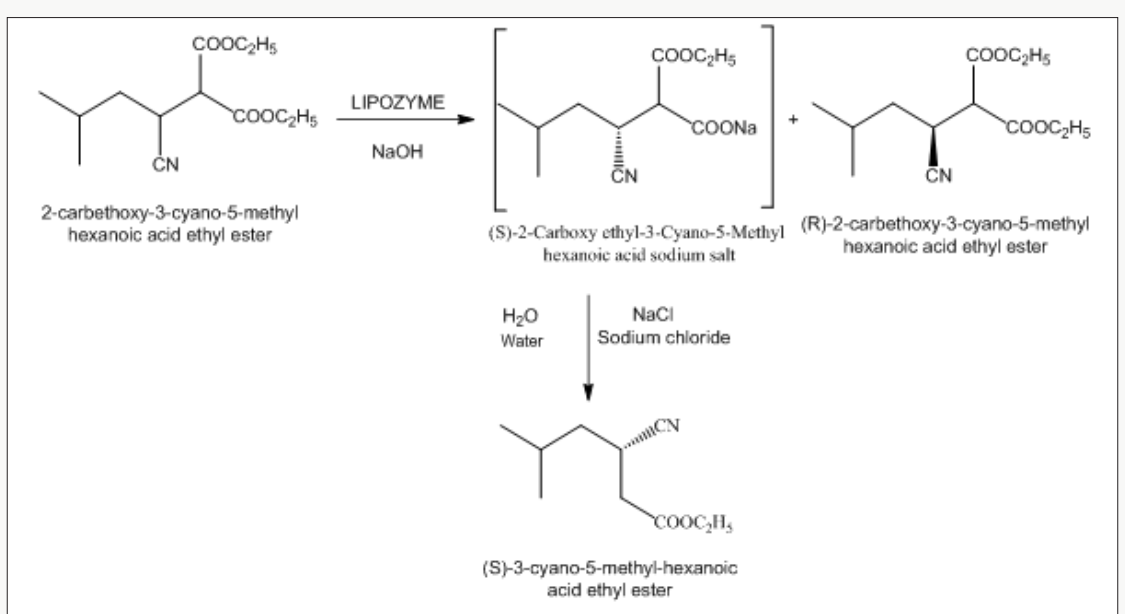

Scheme 4: Preparation of (S)-3-cyano-5-methyl-hexanoic acid ethyl ester.

\section{Preparation of rac-3-cyano-5-methyl-hexanoic acid ethyl ester \\ Preparation of (3S)-3-(Amino methyl)-5-methylhexanoic acid or PREGABALIN}

Describes the reaction wherein the unreacted R-2-carbethoxy3-cyano-5-methyl hexanoic acid ethyl ester is reversed to form

This reaction involves the hydrolysis of ethyl ester, followed by racemic 2-carbethoxy-3-cyano-5-methyl hexanoic acid ethyl ester its hydrogenation with Raney Nickel to yield the final product i.e. using sodium ethoxide (Scheme 5).

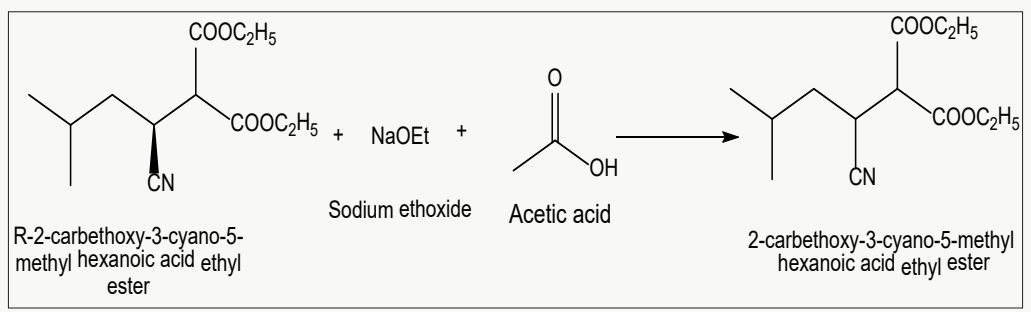

Scheme 5: Preparation of racemic 2-carbethoxy-3-cyano-5-methyl hexanoic acid ethyl ester.

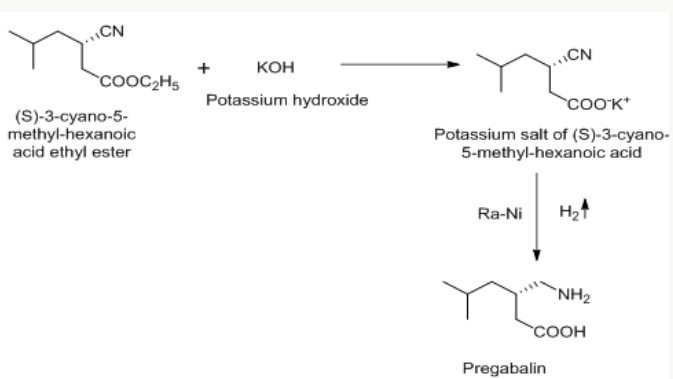

Scheme 6: Preparation of (3S)-3-(Amino methyl)-5-methylhexanoic acid or PREGABALIN. 
Characterization of the 2-Carboxy ethyl-3-Cyano-5-Methyl hexanoic acid tert-butyl amine salt: Detailed characterization was conducted to confirm the structure of 2-Carboxy ethyl-3Cyano-5-Methyl hexanoic acid tert-butyl amine salt intermediate of Pregabalin.

\section{a) IR spectroscopy:}

Instrument used: Perkin Elmer Spectrum one FTIRspectrometer Method used: $1 \% \mathrm{KBr}$ method (Table 3).

Table 3: IR data of the 2-Carboxy ethyl-3-Cyano-5-Methyl hexanoic acid tert-butyl amine salt.

\begin{tabular}{|c|c|c|}
\hline Wave number $\mathbf{( c m}^{-1} \mathbf{~}$ & Assignment & Mode of vibration \\
\hline 3437,3049 & $\mathrm{~N}-\mathrm{H}$ & Stretching \\
\hline $2959,2917,2881,2836$ & Aliphatic C-H & Stretching \\
\hline 2240 & $\mathrm{C} \equiv \mathrm{N}$ & Stretching \\
\hline 1734 & $\mathrm{C}=\mathrm{O}($ Ester $)$ & Stretching \\
\hline 1629 & $\mathrm{C}=\mathrm{O}($ Acid $)$ & Bending \\
\hline 1577 & $\mathrm{~N}-\mathrm{H}$ & Bending \\
\hline $1405,1384,1365$ & Aliphatic C-H & Stretching \\
\hline
\end{tabular}

b) NMR: (Table 4)

Table 4: NMR data of the 2-Carboxy ethyl-3-Cyano-5-Methyl hexanoic acid tert-butyl amine salt.

\begin{tabular}{|c|c|c|c|c|c|}
\hline Position & $1 \mathrm{H}$ & $\mathrm{d}(\mathbf{p p m})$ & $\mathrm{J}(\mathrm{Hz})$ & ${ }^{13} \mathrm{C}$ & DEPT \\
\hline $1,1^{\prime}$ & $6 \mathrm{H}$ & 0.96 & $\mathrm{t}(6.0)$ & $23.21,24.99$ & $\mathrm{CH}_{3}$ \\
\hline 2 & $1 \mathrm{H}$ & $1.78-1.92$ & $\mathrm{~m}$ & 32.57 & $\mathrm{CH}$ \\
\hline $3 \mathrm{Ha}$ & $1 \mathrm{H}$ & $1.34-1.41$ & $\mathrm{~m}$ & \multirow{2}{*}{50.00} & \multirow{2}{*}{$\mathrm{CH}_{2}$} \\
\hline $3 \mathrm{Hb}$ & $1 \mathrm{H}$ & 1.61-1.71 & $\mathrm{m}$ & & \\
\hline 4 & $1 \mathrm{H}$ & 3.55 & $\mathrm{~d}(7.8)$ & 28.58 & $\mathrm{CH}$ \\
\hline 5 & $1 \mathrm{H}$ & 3.3-3.38 & $\mathrm{m}$ & 59.62 & $\mathrm{CH}$ \\
\hline 6 & - & - & - & 173.67 & - \\
\hline 7 & $2 \mathrm{H}$ & 4.23-4.30 & $\mathrm{m}$ & 65.04 & $\mathrm{CH}_{2}$ \\
\hline 8 & $3 \mathrm{H}$ & 1.26 & $\mathrm{t}(6.0)$ & 16.09 & $\mathrm{CH}_{3}$ \\
\hline 9 & - & - & - & 175.07 & - \\
\hline 10 & - & - & - & 54.76 & - \\
\hline $11,11^{\prime}, 11^{\prime \prime}$ & $9 \mathrm{H}$ & 1.37 & $\mathrm{~s}$ & 29.45 & $\mathrm{CH}_{3}$ \\
\hline 12 & - & - & - & 125.25 & - \\
\hline
\end{tabular}

c) Mass spectroscopy: (Table 5)

Table 5: Describes the mass number of the 2-Carboxy ethyl-3Cyano-5-Methyl hexanoic acid tert-butyl amine salt.

\begin{tabular}{|c|c|}
\hline $\mathbf{m} / \mathbf{z}$ & ions \\
\hline 226 & $(\mathrm{M}-\mathrm{H})-$ \\
\hline
\end{tabular}

Optimization of parameters during the preparation of 2-Carboxy ethyl-3-Cyano-5-Methyl hexanoic acid tert-butyl amine salt:

Table 6: $\mathrm{pH}$ variations.

\begin{tabular}{|c|c|c|}
\hline $\mathbf{p H}$ & Reaction time (h) & Yield (w/w) \\
\hline $6-7$ & 36 & 0.49 \\
\hline $7-8$ & 24 & 0.5 \\
\hline $8-9$ & 24 & 0.4 \\
\hline
\end{tabular}

i. $\mathrm{pH}$ variations that were studied are explained in the table below: (Table 6) (Graph 1)

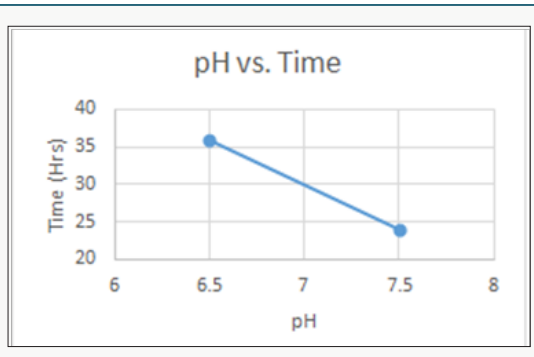

Graph 1: $\mathrm{pH}$ vs. Time variation depicted in Graphical representation.

Table 7: Temperature variations.

\begin{tabular}{|c|c|c|}
\hline Temperature (oC) & Reaction time (h) & Yield (w/w) \\
\hline $20-25$ & 36 & 0.49 \\
\hline $25-30$ & 24 & 0.5 \\
\hline
\end{tabular}

ii. Temperature variations that were studied are explained in the table below: (Table 7) (Graph 2) 


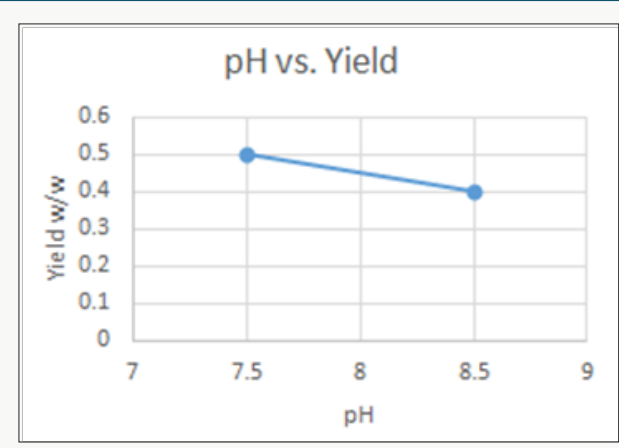

Graph 2: $\mathrm{pH}$ vs. Yield variation depicted in Graphical representation.

\section{iii. Distillation variations}

In the reported procedure, distillation was done at 70-1000C and this led to lesser yield of (S)-3-cyano-5-methyl-hexanoic acid ethyl ester that was prepared in the further reactions. On the other hand, when vacuum distillation was performed, the yield obtained was significantly higher (Table 8).

High vacuum distillation was performed at the end of 2-carbethoxy-5-methyl hex-2-enoic acid ethyl ester since traces of the diethyl malonate impurity would retard the reaction of preparation of (S)-3-cyano-5-methyl-hexanoic acid ethyl ester (Table 9).

Table 8: Purity comparison of 2-carbethoxy-5-methyl hex-2-enoic acid ethyl ester before and after vacuum distillation.

\begin{tabular}{|c|c|c|c|c|}
\hline S.No. & Type & GC purity & Isomer & Diethyl malonate \\
\hline 1. & Before High vacuum distillation & $76.88 \%$ & 11.84 & 3.68 \\
\hline 2. & After High vacuum distillation & $88.23 \%$ & 10.54 & 0.27 \\
\hline
\end{tabular}

Table 9: Yield differences sighted for simple distillation vs. vacuum distillation.

\begin{tabular}{|c|c|c|}
\hline \multirow{2}{*}{ Name of the intermediate } & \multicolumn{2}{|c|}{ Yield (w/w) } \\
\hline & Atmos. distillation & Vacuum distillation \\
\hline $\begin{array}{l}\text { 2-carbethoxy-5-methyl hex-2-enoic acid ethyl } \\
\text { ester }\end{array}$ & 2.52 & 2.4 \\
\hline $\begin{array}{l}\text { 2-carbethoxy-3-cyano-5-methyl hexanoic acid } \\
\text { ethyl ester }\end{array}$ & 0.74 & 1.4 \\
\hline (S)-3-cyano-5-methyl-hexanoic acid ethyl ester & 0.1 & 0.27 \\
\hline
\end{tabular}

This difference shown in the above table was due to degradation of the compound at higher temperatures during distillation that was performed at 70-1000C. Thus, the yield of the subsequent reactions was also affected. So, it was clear that if vacuum distillation was performed in during the preparation of 2-carbethoxy-5-methyl hex-2-enoic acid ethyl ester and 2-carbethoxy-3-cyano-5-methyl hexanoic acid ethyl ester, yield was higher when compared to distillation at temperature 70-1000C.

Purification techniques employed: At certain stages of the Pregabalin synthesis route, purification techniques were employed to increase the yield of the intermediate products of the subsequent stages.

i. Fractional distillation of 2-carbethoxy-5-methyl hex-2enoic acid ethyl ester was done that resulted in the increase in yield of (S)-3-cyano-5-methyl-hexanoic acid ethyl ester.

ii. Column purification of 2-carbethoxy-3-cyano-5-methyl hexanoic acid ethyl ester was also done which in turn increased the purity of (S)-3-cyano-5-methyl-hexanoic acid ethyl ester and 2-Carboxy ethyl-3-Cyano-5-Methyl hexanoic acid ter-butyl amine salt.

\section{Conclusion}

Modifications done in the preparation of 2-carbethoxy-5methyl hex-2-enoic acid ethyl ester indirectly helped improve the yield of (S)-3-cyano-5-methyl-hexanoic acid ethyl ester, during the synthesis of (3S)-3-(Amino methyl)-5-methylhexanoic acid. Higher purity and cheaper cost of the product, are the primary benefits that can be drawn from this improved synthetic procedure of (3S)-3(Amino methyl)-5-methylhexanoic acid. Time saving is yet another advantage of the proposed method of synthesis. Hence, it can be concluded by saying that the proposed method in this manuscript will help modify the existing synthesis of (3S)-3-(Amino methyl)-5methylhexanoic acid and give way to better process.

\section{Acknowledgement}

Our group would like to thank the Department of Scientific and Industrial Research India, Dr. Hari Babu (COO Mylan), Sanjeev Sethi (Chief Scientific Officer Mylan Inc); Dr Abhijit Deshmukh (Head of Global OSD Scientific Affairs); Dr Yasir Rawjee (Head - Global API), Dr Sureshbabu Jayachandra (Head of Chemical Research), Dr. Suryanarayana Mulukutla (Head Analytical Dept MLL API R \& D) as well as analytical development team of Mylan Laboratories Limited for their encouragement and support. We would also like to thank Dr Narahari Ambati (AGC- India IP) \& his Intellectual property team for their support.

\section{References}

1. Frampton JE (2014) Pregabalin: A Review of its Use in Adults with Generalized Anxiety Disorder. CNS Drugs 28(9): 835-854.

2. Hamandi K, Josemir WS (2006) Pregabalin: A new antiepileptic drug for refractory epilepsy. Seizure 15(2): 73-78. 
3. Derek L (2015) Getting To Lyrica. In The Pipeline.

4. Dworkin RH, Kirkpatrick P (2005) Fresh from the Pipeline: Pregabalin. Nature Reviews Drug Discovery. 4(6): 455-456.

5. Bandelow B, Wedekind D, Leon T (2007) Pregabalin for the treatment of generalized anxiety disorder: a novel pharmacologic intervention. Expert Review of Neurotherapeutics 7(7): 769-81.
6. Ryan Patel, Anthony $\mathrm{H}$ Dickenson (2016) Mechanisms of the gabapentinoids and $\alpha_{2} \delta-1$ calcium channel subunit in neuropathic pain. Pharmacology Res Perspectives 4(2): e00205.

7. (2015) Pregabalin. The American Society of Health-System Pharmacists.

8. (2011) Medication Guide US Food and Drug Administration.

\section{(C) (P) \\ This work is licensed under Creative \\ Commons Attribution 4.0 License}

To Submit Your Article Click Here:

Submit Article

DOI: 10.32474/AOICS.2018.01.000115

\section{AOICS}

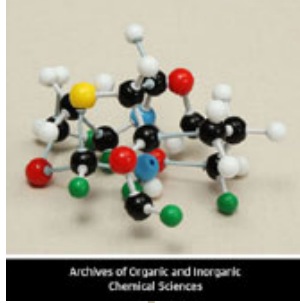

Archives of Organic and Inorganic Chemical Sciences

\section{Assets of Publishing with us}

- Global archiving of articles

- Immediate, unrestricted online access

- Rigorous Peer Review Process

- Authors Retain Copyrights

- Unique DOI for all articles 